\title{
Island Partition in Active Distribution Network Based on CIM
}

\author{
Jiajian HUANG \\ Electric Power Research Institute of Guangdong Power \\ Grid Co., Ltd \\ Guangzhou, Guangdong Province, China \\ E-mail: huangjiajian@gddky.csg.cn
}

Xin LI

Electric Power Research Institute of Guangdong Power Grid Co., Ltd

Guangzhou, Guangdong Province, China

E-mail: lixin@gddky.csg.cn

\author{
Xiaogang XU \\ Electric Power Research Institute of Guangdong Power \\ Grid Co., Ltd \\ Guangzhou, Guangdong Province, China \\ E-mail: xuxiaogang@gddky.csg.cn
}

\author{
Chaoming WANG* \\ Nanjing Soft Core Co., Ltd \\ Nanjing, Jiangsu Province, China \\ E-mail: 77065131@qq.com \\ +* Corresponding author
}

\begin{abstract}
The operation mode after faults in distribution network will be changed due to more and more distributed generations (DGs) integrated into distribution network with their additional service ability. And the above mode is carried out based on the different bus information, such as the value of active power and reactive power, load information, et al. The common information model (CIM) of distribution network can provide the above measuring data of different buses. Based on the CIM, the topology and measurement model is built and the sequence diagram of the island partition method is constructed, in which the unit merging algorithm is used. Thus, the island partition scheme is obtained. To obtain more reasonable scheme, consideration of node electrical coupling connectivity metric is involved to distinguish the priority of key buses integrating to certain island. The simulation results with certain distribution network benchmark shows the effectiveness of topology and measurement model and the consistency of improved unit merging algorithm.
\end{abstract}

Keywords-active distribution network; island partition; improved unit merging algorithm; distributed generation; CIM

\section{INTRODUCTION}

In recent years, with the increment of capacity of distributed generations (DGs) integration into distribution network, the operation mode of distribution network after fault has also changed.

In the traditional load distribution network the power source is single, and the service is provided by the only power distribution transformer. If the fault happens in certain feeder line, power fault section will be isolated by some switches operation, and then the distribution transformer will restore the service of non-faulted zone. If the distribution transformer fails, the corresponding power supply region will go into a complete blackout. A large number of DGs are connected to distribution network, which allow the distribution network with additional service ability of some DGs to certain important load zone. Before the above operation, DG power supply capacity and the surrounding load demand need to match the power, so as to ensure the stability of the power supply after the fault and the good power quality. Therefore, it becomes increasingly important to study the islanding method for distribution networks with DGs integration [1]-[3].

There are many methods to research islands partition scheme with DG. Reference [4] takes the DG with the maximum capacity as the tree root, establishing the power tree and using enumeration method, to obtain the initial division plan, but the computation quantity is large. Reference [5] takes DG as the power circle center, and determines the island load attribution by defining the power circle, but does not involve the merging treatment of the two islands intersection load. Reference [6] and [7] used the branch \& bound algorithm and depth-first dynamic programming algorithm based on tree knapsack theory, and used the "search and then check" to obtain the optimal island partition strategy, the theory of this method is better, but the work is heavy. Reference [8] from the optimal power point, expands the power supply range line by line, but the selection level of the first power point in this method is much higher. The active fault restoration of distribution network is divided into preliminary isolation, residual network merging and islanding resynchronization in [9], which is attributed to the power recovery of transmission grid, has good effect but requires a long time. In reference [10] island restoration process is divided into two stages, the stage of solving tree knapsack problem and island security check stage. The above methods do not make full use of the information data collected by the distribution network, and the scheme is an approximate scheme. The importance of load nodes in the above algorithm are set artificially, not according to the topology of the power network with the method of quantitative analysis, and failed to make full use of a large number of effective monitoring data in the operation of distribution network.

With the development of distribution network and the increment of monitoring points, and the establishment of distribution network CIM model, the reasonable operation of distribution network management based on the 
information of CIM model are the future directions. At present, the work has already started. In Reference [11], based on CIM model of distribution network, the calculation of distribution network loss is carried out. Based on the CIM model, the fault information category of distribution network is established on the basis of [12] model, and the fault diagnosis research of distribution network is carried out.

This paper intends to expand the application field of the CIM of distribution network, considering the effect of DGs connected into the feeder line at different position with different capacity. And then the author made full use of monitoring information in the distribution network, calculating local balance between loads and sources to divide islands zone after the distribution network fault. On the basis of that, the importance of load nodes is quantitatively sorted by using the index of node electrical coupling connectivity, which provides guidance for the direction of island division, and ensures the stability of the following islanding operations.

\section{CIM Model Of Distribution Network ASSOCIATED WITH ISLANDING}

Classes are used to represent equipments and corresponding connections between components and elements in distribution network CIM as in [11] and [12]. The elements and models related to islanding operation mainly include the measurement model of the distribution network, the topological model and the CIM model of the line. The measurement model includes voltage and current data of the connections nodes (switch); topology model data relating to electrical equipment, connection, topology. Sequence feeder line impedance and admittance parameter are mainly involved in the line CIM model. And the topology model is as follows in Fig.1.

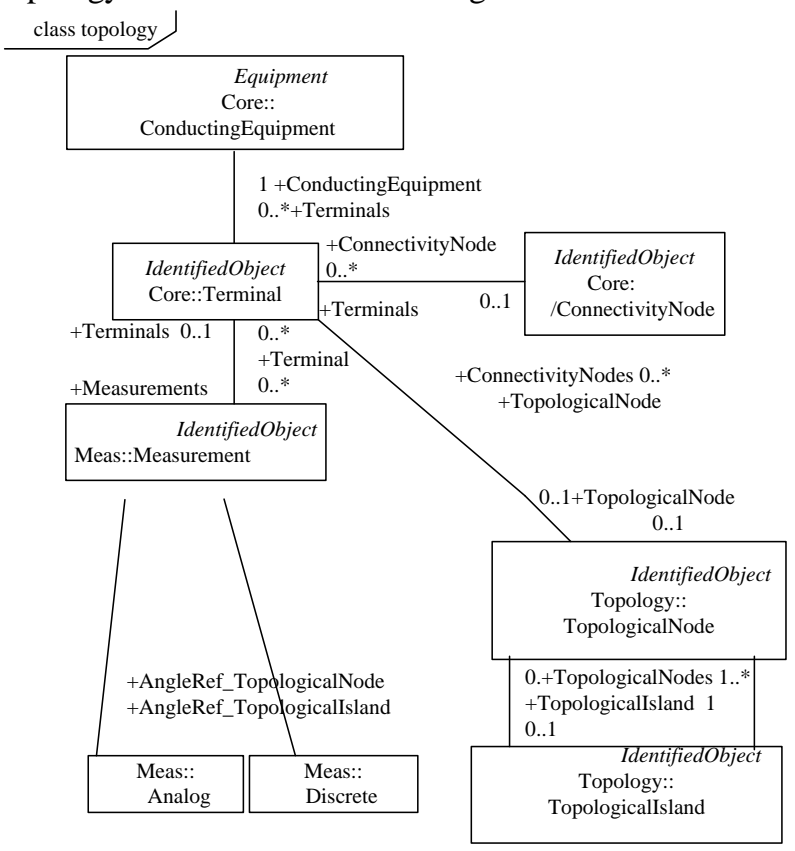

Figure 1. Topology and measurement model
The data actually used for islanding operation can be obtained from the network, topology and marketing data, and according to the measurement model, topological model and line CIM model, a distribution network model for islanding is established.

The sequence of information input in island partition is as follows. Firstly, the topology model is analyzed. According to the introduced topology data, the connection between equipments and the open statuses of switches are obtained. Secondly, all network information concerning equipment and buses is introduced. Finally, according to the information from the measurement and sampling system, the island partition calculation is carried out. And the above sequence diagram is seen in Fig.2, in which the transfer sequence is demonstrated between different objects.

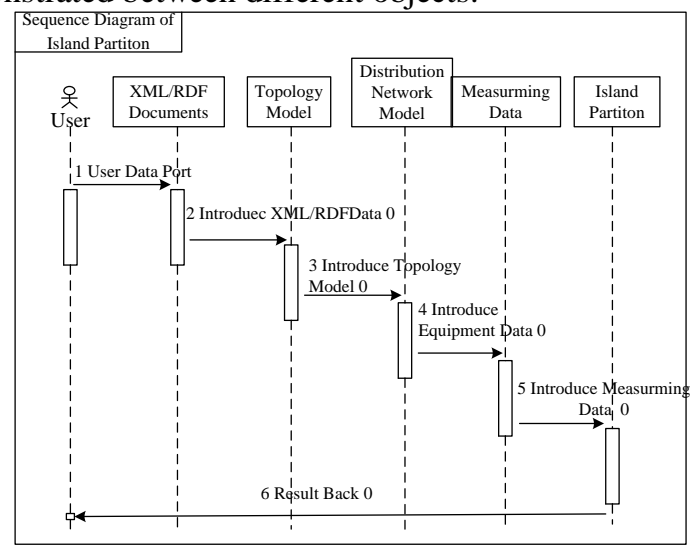

Figure 2. Sequence diagram of island partition

\section{Unit Merging Algorithm}

The initial islanding algorithm used in this paper is unit merging algorithm, and this method can effectively use realtime load flow data in the multi-point distribution network with the more integration of distribution network CIM model, to realize island partition after the fault of distribution network.

The algorithm defines circuit breaker or control points in the line (connecting nodes in the CIM model) as a node, dividing a scope which contains the load as a load unit, dividing a scope which contains the power source as a source unit. Among which, the load unit power value is negative, which reflects the amount of consumed power. The power value of the source unit is positive, which reflects how much the power is injected into the grid.

According to the above definition, any complex distribution network can be regarded as a composite network composed of several source units and load units. For a composite network, the two adjacent units can be merged under certain conditions. The action of merging two units is called unit fusion. Specific fusion rules are as follows:

- The two units fused must be adjacent to each other (there must be a common node).

- The two units fused, whose power algebra must be greater than or equal to zero (the basic condition for islanding operations). 
- The algebraic sum of two units' power before fusion is defined as the power of the new unit after merging.

- The nodes between the two units before merging (i.e., the measurement points between two units), or all the nodes that contact each other, are removed after fusing, only retain the nodes that do not touch each other, and exist as nodes of the new unit.

- The scope of the new unit is the range of the two units involved in the integration.

The specific fusion process is shown in Fig. 3. The fusion process takes into account the class attributes of the load and selectively preferentially loads important loads so as to form an island of reliable operation

The fusion process should take into account the class attributes of the load, selectively and preferentially fuse the important loads so as to form a reliable operating island.

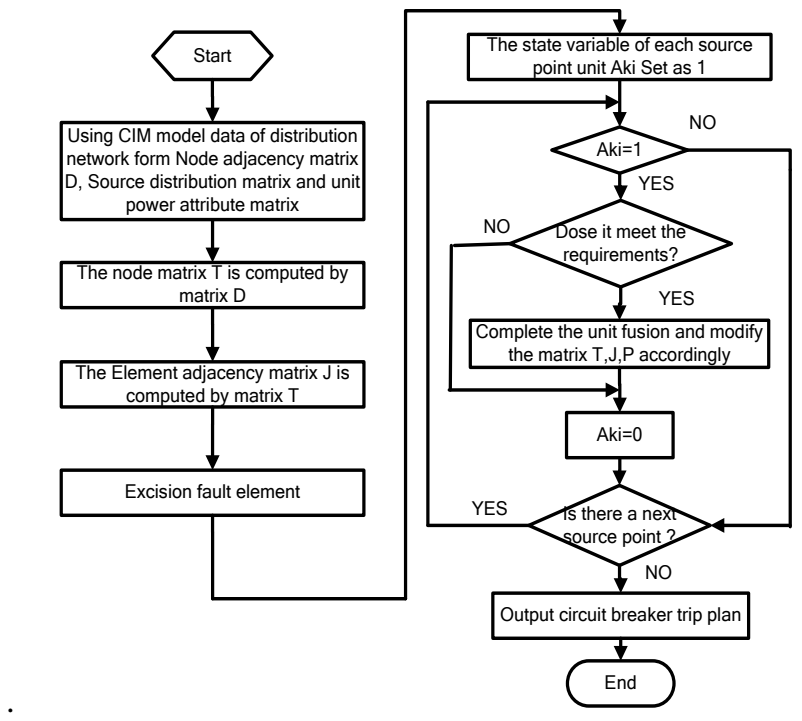

Figure 3. Algorithm flow chart

\section{Node Electrical Coupling Degree Index DESIGN}

The unit fusion method can't distinguish the difference of nodes importance in island partition of the distribution network based on the connection degree of each node (the number of connections with the surrounding nodes). Reference [13] shows that nodes with high connectivity degree are not necessarily key nodes. Therefore, in the islanding process of unit fusion method, identification of some important nodes is needed in the distribution network to ensure the power supply priority to these important load nodes and improve the reliability of distribution network operation.

Based on the consideration of some parameters of the distribution network, such as line length, line impedance, network structure, load flow trends, combined with the superposition theorem, the concept of node electrical coupling connectivity is used to define the importance of each node in the distribution network.

\section{A. Electrical Distance}

In the distribution network, the electrical distance between nodes $\mathrm{m}$ and $\mathrm{n}$ can be represented by the equivalent

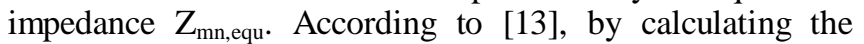
parameters of the system node impedance matrix, the equivalent impedance $Z_{m n \text {,equ }}$ between any node in the distribution network is obtained, as shown in equation (1), where $Z_{\mathrm{mn}}$ is the system node impedance matrix corresponding element.

$$
Z_{m n, e q u}=\left(Z_{m m}-Z_{m n}\right)-\left(Z_{m n}-Z_{n n}\right)
$$

\section{B. Node Electrical Coupling Degree}

Suppose that a distribution network contains $\mathrm{N}$ nodes, then the electrical coupling degree of any node $\mathrm{m}$ in the network, denoted as $\mathrm{D}_{\mathrm{e}, \mathrm{m}}$, is:

$$
D_{e, m}=1 / \sum_{n=1, m \neq n}^{n=N} Z_{m n, e q u}
$$

The upper expression is used to indicate the importance of each node in the distribution network, i.e., the reciprocal of the sum of the equivalent impedance values between the node $\mathrm{m}$ and the other nodes in the distribution network. The electrical coupling of nodes can quantify the degree of importance of nodes, thus making it clearer to determine which nodes should be preferentially powered. Obviously, the greater the value of $D_{e, m}$ is, the closer the node $m$ is to the rest nodes, and the more important the node position is in the distribution network. For load nodes, the greater the electrical coupling degree is, the smaller the electrical distance is, and the more priority the service is supplied. In the above condition, the smaller the network loss, the power supply margin indirectly increases, and the stability of islanding operation is obtained.

On the improvement of traditional unit fusion algorithm, only the node electric coupling calculation of each load node in the fault unit is carried out, sized and sorted. And in the following fusion process, electrical coupling degree is calculated before fusion operation in the load units on the two adjacent, and the node with more connection degree, is preferred into fusion.

\section{EXAMPle ANAlysis OF TyPICAL 12 NoDE DiSTRIBUTION SYSTEM}

In this paper, a typical example of a 12 node distribution network in a certain area is used to demonstrate the consideration of increasing the electrical coupling degree of the nodes, which can enhance the utilization of the regional power capacity after islanding in the distribution network. The measurement data can be obtained from the connection switch in the measurement model, and the line impedance data can be obtained from the order parameter of the CIM model of the distribution network.

Examples include 1 distribution transformer nodes, 3 DG nodes, and 8 load nodes, as shown in Fig. 3. Specific 
parameters are shown in Table I. The connection between the power supply and the load, the load and the load is bounded, and the 12 node system can be equivalent to the unit topology connection system shown in Fig. 4. The shaded part represents the source point unit, the dotted area represents the load unit, and the line switch is renumbered. In Fig. 4, the connection switch $\mathrm{B}_{\mathrm{i}}$ stands for the measurement node $\mathrm{i}$ with $\mathrm{i}=1 \ldots 11$.

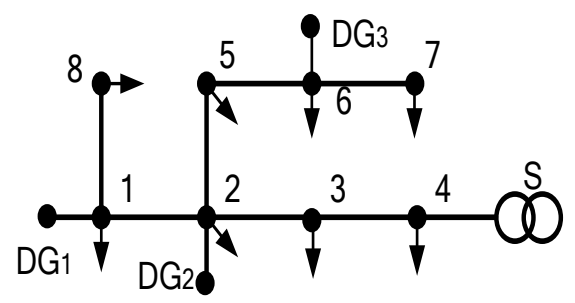

Figure 4. Typical 11-buses distribution network diagram

TABLE I. TYPE AND POWER VALUE OF UNITS

\begin{tabular}{|c|c|c|c|}
\hline Node & Power & Node & Power \\
\hline DG1 & 50 & Load 4 & -30 \\
\hline DG2 & 30 & Load 5 & -20 \\
\hline DG3 & 40 & Load 6 & -30 \\
\hline Load 1 & -20 & Load 7 & -30 \\
\hline Load 2 & -10 & Load 8 & -30 \\
\hline Load 3 & -20 & & \\
\hline
\end{tabular}

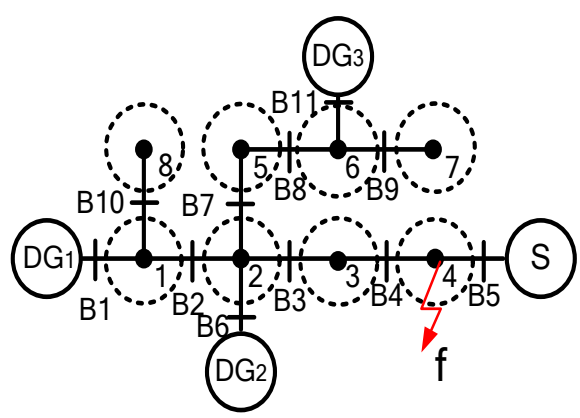

Figure 5. Structure diagram of initialunits

\section{A. Island Partition Results by Traditional Fusion}

Assume that load node 4 in Fig. 5 fault, the traditional fusion algorithm results is shown in Fig. 6, in which the open switch node numbers are B4, B5, B9, B10. The total capacity of the distributed power supply is $120 \mathrm{~kW}$, and the actual power supply area covers the load capacity of $100 \mathrm{~kW}$, and the utilization ratio of the power supply capacity is $83.33 \%$.

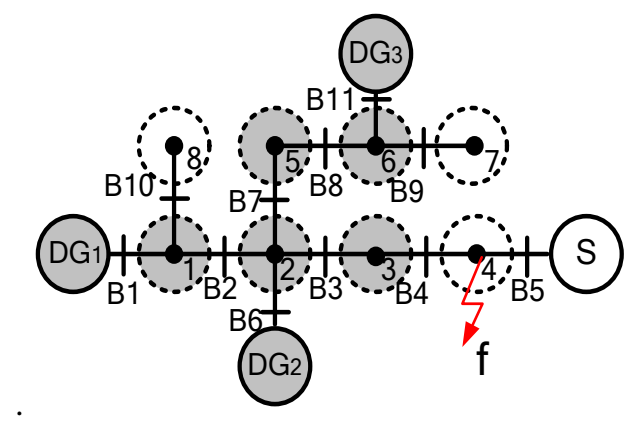

Figure 6. Island partition results diagram

\section{B. Island Partiton Results by Improved Unit Fusion}

Electrical connection node coupling degree is greater, the fusion priority is higher. By using (2), the electrical coupling degree matrix $\mathrm{D}_{\mathrm{e}, \mathrm{i}}$ of the whole system node can be obtained:

$$
\begin{aligned}
& D_{e, i}=\left[\begin{array}{llll}
0.0295_{\text {Source } 1} & 0.0297_{\text {Source } 2} & 0.0274_{\text {Source } 3} & 0.0256_{\text {Source4 }}
\end{array}\right. \\
& 0.0251_{\text {Lood1 } 1} \quad 0.0249_{\text {Lood } 2} \quad 0.0219_{\text {Lood3 } 3} \quad 0.0226_{\text {Lodd }} \\
& 0.0163_{\text {Load5 }} \quad 0.0146_{\text {Load } 6} \quad 0.0115_{\text {Lod } 7} \quad 0.0263_{\text {Load8 }} \text { ] }
\end{aligned}
$$

The first row of the matrix corresponds to the 4 source point units, and the following is marked with Source $i$ $(\mathrm{i}=1, \ldots, 4)$, the second and third rows correspond to 8 load units in turn, with subscript Load i $(\mathrm{i}=1, \ldots, 8)$.

According to [13], the electrical coupling degree of the source unit is usually large. The electrical coupling degree of the first 4 units in the above matrix is relatively large, and it conforms to the distribution rules of the electrical coupling junction of the node. The unit fusion process begins from source unit, so this paper focuses on load node electrical coupling degree sorting, which relates to the fusion sequence of load unit.

According to the topological diagram, when the source point unit DG1 is fused with the load unit 1, there are two choices, namely, the fusion load unit 2 or the load unit 8 can be selected. According to the electrical coupling degree of the node above, the coupling degree of load 2 is 0.0249 , less than the coupling degree of load 8 which is 0.0263 . Thus, the load unit 8 can be selected into fusion preferentially, the load unit 2 and other units later.

After fusion, open switch node numbers are B3, B4, B5 and B9, the results shown in Fig. 7. The total capacity of the distributed power supply is $120 \mathrm{~kW}$, and the actual power supply area covers the load capacity of $110 \mathrm{~kW}$, and the utilization ratio of the power supply capacity is $91.67 \%$. 


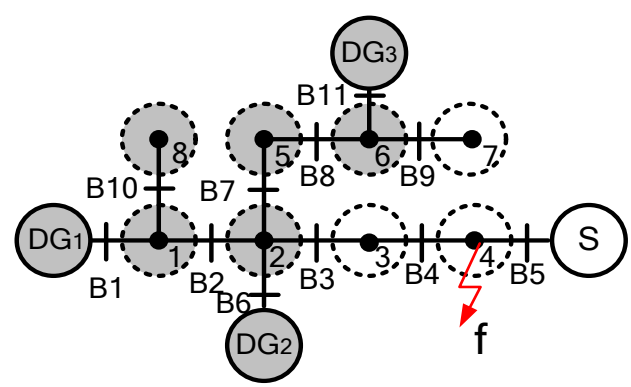

Figure 7. Island partition results based on node electrical coupling connectivity index

The island partition results comparison of the two fusion algorithm are shown in Table II.

TABLE II. ISLAND PARTITION SCHEME COMPARISON OF TWO FUSION ALGORITHM

\begin{tabular}{|c|c|c|}
\hline & Traditional Algorithm & Improved Algorithm \\
\hline Switch in Open & B4, B5, B9, B10 & B3,B4,B5,B9 \\
\hline Source Capacity & $120 \mathrm{~kW}$ & $120 \mathrm{~kW}$ \\
\hline $\begin{array}{c}\text { Load Capacity } \\
\text { in Service }\end{array}$ & $100 \mathrm{~kW}$ & $110 \mathrm{~kW}$ \\
\hline $\begin{array}{c}\text { Utilization Ratio } \\
\text { of Source }\end{array}$ & $83.33 \%$ & $91.67 \%$ \\
\hline
\end{tabular}

According to comparison results, the load capacity in service increased $10 \mathrm{~kW}$, and power supply capacity utilization rate increased from $83.33 \%$ to $91.67 \%$. Therefore, the effectiveness of node electrical coupling connectivity index is verified obviously.

\section{CONCLUSION}

The author constructed the sequence diagram of the island partition method based on the topology and measurement model due to the common information model (CIM). In addition, the unit merging algorithm is used to obtain the island partition scheme base on the above bus measuring data. A node electrical coupling connectivity index is introduced into the island partition process to improve the reasonable character of distribution network operation mode after-faults. The simulation verified the effectiveness of the above island partition scheme.

\section{ACKNOWLEDGMENT}

The work is supported by the Project of Science Research of Nanjing Soft Core Co.,Ltd, China.

\section{REFERENCES}

[1] YANG Xinfa, SU Jian, LU Zhipeng, LIU Haitao and LI Rui, "Overview on micro-grid technology," Proceedings of the CSEE, vol. 34(1), pp. 57-70, 2014

[2] LU Zhigang and DONG Yuxiang. "Service Restoration Strategy for the Distribution System with DGs," Automation of Electric Power Systems, vol. 31(1), pp. 89-92. 2007.

[3] DING Lei, PAN Zhencun and CONG Wei, "Searching for international islanding strategy of distributed generation based on rooted tree,” Proceedings of the CSEE, vol. 28(25), pp. 62-67,2008

[4] XIANG Yue, LIU Junyong, YAO Liangzhong, et al. "Optimization strategy for island partitioning and reconfiguration of faulted distribution network containing distributed generation," Power System Technology, vol. 37(4), pp. 1025-1032, 2013.

[5] LIU Chuanquan and ZHANG Yan, "Distribution network reliability considering distribution generation," Automation of Electric Power Systems, vol. 31(22), pp. 46-48, 2007.

[6] WANG Xudong and LIN Jikeng, "Island partition of the distribution system with distributed generation based on branch and bound algorithm," Proceedings of the CSEE, vol. 31(7), pp. 16-20, 2011.

[7] WANG Xudong and LIN Jikeng, "Island partition o1 the distribution system with distributed generation," Science in China Technology Science, vol. 41(1), pp. 1-10, 2011.

[8] YU Wenpeng, LIU Dong and WEN Jiaming, "A power restoring model for distribution network containing distributed generations and improved greedy algorithm,” Automation of Electric Power Systems, vol. 37 (24), pp. 23-30, 2013.

[9] PHAM.T. T. H, BESANUER. Y, HADJSAID. N, "New challenges in power system restoration with large scale of dispersed generation insertion,”. IEEE Trans on Power Systems, vol. 24(1), pp.398-406, 2009.

[10] JIKENG L, XUDONG W, PENV W, et al. "Two-stage method for optimal island partition of distribution system with distributed generations," IET Veneration, Transmission \& Distribution, vol. 6(3), pp. 218-228, 2012.

[11] HAO Sipeng, CHU Chengbiao,FANG Quan,ZHANG Yangfei and KAN Jianfei, "Calculation of the Distribution Network Line Loss Based on CIM", Electrical Measurement \& Instrumentation, vol. 51(17), pp. 18-23, 2014.

[12] HAO Cuijuan. "Research on Diagnosis and Isolation Algorithm for Distribution Network Using CIM"[D]. Beijing: North China Electric Power University, 2012.

[13] TAN Yudong, LI Xinran, CAI Ye and ZHANG Yudong, "Critical Node Identification for Complex Power Grid Based on Electrical Distance," Proceedings of the CSEE, vol. 34(1), pp. 146-152, 2014. 